\title{
Relationship between Knowledge Management Enablers and Knowledge Creation Internalisation in the Nepalese Hospitality Industry
}

\author{
Pushpa Maharjan, $\mathrm{PhD}^{*}$
}

DOI: https://doi.org/10.3126/jnbs.v13i1.34697

\section{ABSTRACT}

This paper examines the relationships between the knowledge management enablers and knowledge creation internalisation in the hospitality industry such as hotel, travel and trekking agencies in Nepal. The Nepalese hospitality industry is very competitive. Knowledge is a resource to gain a competitive advantage in this sector. It requires obtaining comprehensive information on how knowledge is managed and utilized in the hospitality industry. It is also necessary to examine the organisational culture, structure, information technology and knowledge creation internalisation that are essential in managing the performance in the hospitality industry to make it more efficient. The study is based on primary data with 382 responses. The self-administered questionnaires were used to collect the perceptive opinions from the respondents. The descriptive quantitative research designs and regression analysis were applied to develop an understanding of the research issue from 38 hotels and 59 travel and trekking agencies of Nepal stationed in the capital Valley of Kathmandu. The study concludes that the key knowledge management enablers such as collaboration, trust, learning, and information technology do influence the knowledge creationinternalization positively. Managers should promote collaboration, trust, learning and information technology facilities for employees to create knowledge in organisation.

Keywords: Hospitality industry, knowledge creation internalisation, knowledge management enablers

*Dr. Maharjan is an Assistant Professor at Public Youth Campus, Tribhuvan University.

Email: s3pushpam@gmail.com 


\section{INTRODUCTION}

Coleman (1999) indicated that knowledge management is an umbrella term for a wide variety of interdependent and interlocking functions consisting of knowledge creation, knowledge valuation and metrics, knowledge mapping and indexing, knowledge transport, storage, distribution and knowledge sharing. In the same year Scarbrough, Swan and Preston (1999) defined knowledge management as the process of creating, acquiring, capturing, sharing, and using knowledge for the boost of organisational learning and performance. For Robinson, Carrillo, Anumba and Al-Ghassani (2005) knowledge management is a method of exploiting or transforming knowledge as an asset for organisational use to help continuous improvement.

Internalisation (explicit to tacit knowledge) is the absorption of explicit knowledge into tacit. It is very similar to learning through practice. Internalisation is facilitated if individual knowledge is explained in words or documented. Simulations are another way to achieve this conversion. This internalisation requires, firstly, the updating of the concepts or methods explicit and, secondly, the inclusion of such explicit knowledge into tacit (Nonaka \& Konno, 1998) using some tools such as metaphor. But it is also necessary that explicit knowledge is lived or experienced, either from the personal experience of doing an activity, either through participation, simulations, or role-playing exercises, so that they internalize it in their style and habits. In this way individuals use this stage to expand, extend and transform their tacit knowledge, starting again a new cycle (Nonaka, 1991). New explicit knowledge created by the combination should be assimilated by the members of the company to be used properly (Nonaka, 1994). The combination allows explicit knowledge to be captured in the phase of internalisation by individuals that extend, expand and transform this knowledge explicitly (Nonaka, 1994; Nonaka \& Konno, 1998). Through internalisation, knowledge from the combination is transformed into organisational memory and is actualized in practical operations such as new product development or manufacturing procedure (Nonaka, Toyama, \& Nagata, 2000). So, new higher explicit knowledge obtained and shared through the combination is applied and used in practical situations that are the basis of new organisational routines, and then new tacit knowledge is made by individuals of the organisation through the process of internalisation (Nonaka, 1991; Nonaka, 1994; Nonaka \& Takeuchi 1995; Nonaka et al., 2000; Nonaka \& Toyama, 2003).

Finally, exercising $b a$ involves the conversion of explicit to tacit knowledge through the internalisation process. The ' $b a$ ' represents a contextual place shared with others from which relationships emerge, and within which knowledge is exchanged or shared. This place may be physical, virtual, or mental, or a combination of these. Thus, exercising ba entails a space for active and continuous individual learning (Alavi \& Leidner, 2001). Kuhlen (2003) stated that transformation of explicit knowledge into tacit knowledge mainly through learning, simulation and reorganisation. Understanding the characteristics of various $b a$ and 
the relationship with the modes of knowledge creation is important to enhancing organisational knowledge creation.

Internalisation facilitates the conversion of the organisation's explicit knowledge into personal and team level tacit knowledge (Vaccaro, Veloso, \& Brusoni, 2009). Bolloju, Khalifa, \& Turban (2002) suggested that internalisation occurs once explicit knowledge becomes tacit, whereby organisation members put together collective explicit knowledge using previous information for updating mental representations and producing new tacit knowledge. Thus, it is apparent that internalisation is a process of converting the combined and structured explicit ideas into a more action-oriented form of knowledge that can be shared effectively among various levels of employees in an organisation (Bolloju et al., 2002; Vaccaro et al., 2009). However, Li and Hsieh (2009) believed that knowledge stickiness (incapability in transferring knowledge) in project teams may generate negative impacts towards internalisation, if deliberately transferring knowledge to supplementary firms turns out to be costly and tedious. Therefore, the level of internalisation also can become more difficult and complicated if the vast knowledge and information that needs to be converted to tacit knowledge is increasingly complex.

Choi (2002), Lee and Choi (2000), and Migdadi (2005) found that collaboration is related tointernalisation. But Berraies, Chaher, and Yahia (2014) found that collaboration is not related tointernalisation. Choi (2002), Lee and Choi (2000), and Migdadi (2005) found that trust is significant forinternalisation. But Berraies et al. (2014) found that trust is not related tointernalisation. Learning is a significant predictor of internalisation (Choi, 2002; Lee \& Choi, 2000; Berraies et al., 2014 \& Migdadi, 2005). Migdadi (2005) found that the centralisation is not a significant predictor of internalisation. But Choi (2002), Berraies et al. (2014), and Lee and Choi (2000) found that centralisation is a significant negative predictor of internalisation. Choi (2002), Lee and Choi (2000), Berraies et al. (2014), and Migdadi (2005) found that formalisation is not a significant predictor of internalisation. Berraies et al. (2014) concluded that information technology is a good predictor of internalisation. Choi (2002), Lee and Choi (2000), and Migdadi (2005), who found that information technology is not a good predictor of internalisation.

$\mathrm{Ng}$, Goh and Eze (2011) examined that knowledge management plays a relatively important role in product development performance as far as socialisation, externalisation, combination and internalisation processes are concerned. Also, from the literature review, it is found that socialisation and internalisation implementations exhibit a stronger role in enhancing product development performance. Managers and engineers should work together to create more platforms that can harness socialisation activities such as coffee klatches, technical sharing and team building activities. This will help to enhance the socialisation activities among product development teams. Besides, management should also emphasize the process of internalizing explicit knowledge that actualizes concepts about strategy, tactics, 
innovation, or improvement. For example, training programs should be held in organisations to help employees understand the organisation and themselves as a whole.

Chaudhary (2016) stated that Nepalese banks lack the culture of informal dialogues and meetings for sharing and acquiring new knowledge and ideas among themselves. Kandel (2015) viewed that several departments within their organisation get together periodically to plan a response to changes taking place in their business environment. Chalise $(2006,2011)$ suggested that there is still a need to develop metaphors and analogies to describe what the Nepalese banking industry know.

In the above discussed context, the objective of the paper is to evaluate the relationship between knowledge management enablers and knowledge creationinternalisation in the business enterprises of sectors such as hotel, travel and trekking agencies. Knowledge is a resource for gaining a competitive advantage in this sector. It requires obtaining comprehensive information on how knowledge is managed and utilized in the hospitality industry. It is also necessary to examine the organisational culture, structure, information technology and knowledge creation internalisation that are essential in managing the performance in the hospitality industry to make it more efficient. The remaining part of the paper has been divided into four sections. The second section presents the review of the literature, the third section reveals the research method, the fourth section exposes results and the final section presents the conclusion of the study.

\section{LITERATURE REVIEW}

The organisation culture determines not only what knowledge is valuable, but also what knowledge must be maintained for sustainable innovative advantage (Long, 1997). It is also important to note that for successful implementation of knowledge management practices, major cultural change is often necessary. The traditional rewarding system based on individual performance should be exchanged for a new system that esteems knowledge sharing (Jeng \& Dunk, 2013).

Schein (1985) defined organisational culture as a set of implicit assumptions held by members of a group that determines how the group behaves and responds to its environment. At its deepest level, culture consists of core values and beliefs that are embedded tacit preferences about what the organisation should strive to attain and how it should do it (DeLong \& Fahey, 2000). These tacit values and beliefs determine the more observable organisational norms and practices that consist of rules, expectations, rituals and routines, stories and myths, symbols, power structures, organisational structures, and control systems (Bloor \& Dawson, 1994; Johnson, 1992).

Collaboration is an important feature in knowledge management adoption. It is defined as the degree to which people in a group actively assist one another in their task (Hurley \& Hult, 1998; Lee \& Choi, 2003). A collaborative culture in the workplace 
influences knowledge management as it allows for increased levels of knowledge exchange, which is a prerequisite for knowledge creation. This is made possible because collaborative culture eliminates common barriers to knowledge exchange by reducing fear and increasing openness in teams (Lee \& Choi, 2003).

Trust can be defined as maintaining reciprocal faith in each other in terms of intention and behaviors (Kreitner \& Kinicki, 1992). By alleviating the fear of risk and uncertainty, trust encourages a climate conducive to better knowledge creation. Trust is critical in a crossfunctional or inter-organisational team because withholding information because of a lack of trust can be especially harmful to knowledge articulation, internalisation, and reflection (Hedlund, 1994). Distrust leads people to hide or hoard their knowledge (Jarvenpaa \& Staples, 2000). In a distrusted environment, knowledge will not be created or will be created in a restrictive manner. Therefore, facilitating trust among cross-functional or interorganisational team members is important for the foundation of knowledge creation (Ichijo et al., 1998; Lubit, 2001; Nelson \& Cooprider, 1996; Scott, 2000).

The capacity of knowledge creation can be increased by various learning means such as education, training, and mentoring. Krogh (1998) proposed training programs as a means of knowledge creation. Swap, Leonard, Shields and Abrams (2001) highlighted mentoring as a key means in creating organisational knowledge. Intense mentoring enables professionals to obtain a higher level of knowledge. For the organisations to be successful in knowledge creation, traditional training and development activities may no longer suffice; they need to nurture an environment with continuous and persisting learning (Lubit,2001; Eppler \& Sukowski, 2000).

Centralisation refers to the locus of decision authority and control within an organisational entity (Caruana, Morris, \& Vella, 1998). The concentration of decision-making authority inevitably reduces creative solutions while the dispersion of power facilitates spontaneity, experimentation, and the freedom of expression, which are the lifeblood of knowledge creation (Graham \& Pizzo, 1996). Therefore, many researchers proposed that a centralized organisational structure makes it harder to create knowledge (Teece, 2000). Moreover, centralised structure hinders interdepartmental communication and frequent sharing of ideas due to time-consuming communication channels (Bennett \& Gabriel, 1999); it also causes distortion and discontinuousness of ideas (Stonehouse \& Pemberton, 1999). Without a constant flow of communication and ideas, knowledge creation does not occur.

Formalisation is an obstacle on the way towards externalisation, integration, and internalisation processes. Zucker, Darby, Brewer and Peng (1996) have found that less centralisation and formalisation can lead to higher degrees of knowledge management implementation and process flow at all levels of the organisation. 
Technology is a powerful enabler of knowledge management success. It is generally accepted that databases, intranets, knowledge platforms and networks are the main blocks that support knowledge management. Information Technology facilitates quick search, access of information, cooperation and communication between organisational members (Yeh, Lai, $\&$ Ho, 2006). There is an extensive collection of information technologies such as data warehousing, intranet, internet, which can be implemented and integrated in an organisation's technological platform and work together as a knowledge management system. Luan and Serban (2002) grouped information technologies into more than one category: business intelligence, knowledge base, collaboration, content and document management, portals, customer relationship management, data mining, workflow, search, and e-learning.

Internalisation (explicit to tacit knowledge) is the absorption of explicit knowledge into tacit. It is very similar to learning through practice. Internalisation is facilitated if individual knowledge is explained in words or documented. Simulations are another way to achieve this conversion. This internalisation requires, firstly, the updating of the concepts or methods explicit and, secondly, the inclusion of such explicit knowledge into tacit (Nonaka \& Konno, 1998) using some tools such as metaphor. But it is also necessary that explicit knowledge is lived or experienced, either from the personal experience of doing an activity, either through participation, simulations, or role-playing exercises, so that they internalize it in their own style and habits. In this way individuals use this stage to expand, extend and transform their own tacit knowledge, starting again a new cycle (Nonaka, 1991).

Choi (2002) stated that collaboration, trust and learning are a good predictor of internalisation. As well Lee and Choi (2000), and Migdadi (2005) found that collaboration is related tointernalisation. Lee and Choi (2000), and Migdadi (2005) found that trust is significant with internalisation. But Berraies et al. (2014) found that trust is not related with internalisation. Learning is a significant predictor of internalisation (Lee \& Choi, 2000; Berraies et al., 2014; Migdadi, 2005). Migdadi (2005) found that the centralisation is not a significant predictor of internalisation. But Choi (2002), Berraies et al. (2014), and Lee and Choi (2000) found that centralisation is a significant negative predictor of internalisation. Choi (2002), Lee and Choi (2000), Berraies et al. (2014), and Migdadi (2005) found that formalisation is not a significant predictor of internalisation. Berraies et al. (2014) concluded that information technology is a good predictor of internalisation. Choi (2002), Lee and Choi (2000), and Migdadi (2005), who found that information technology is not a good predictor of internalisation.

As stated in the previous section, the main objective of the study is to develop a theoretical model of knowledge management enablers for knowledge creation internalization in the Nepalese hospitality industry. The conceptual categories are developed based on the review of previous researches. The conceptual categories that were established for the conceptual model are the knowledge management enablers to knowledge creation internalisation. 


\section{Knowledge Management Enablers}

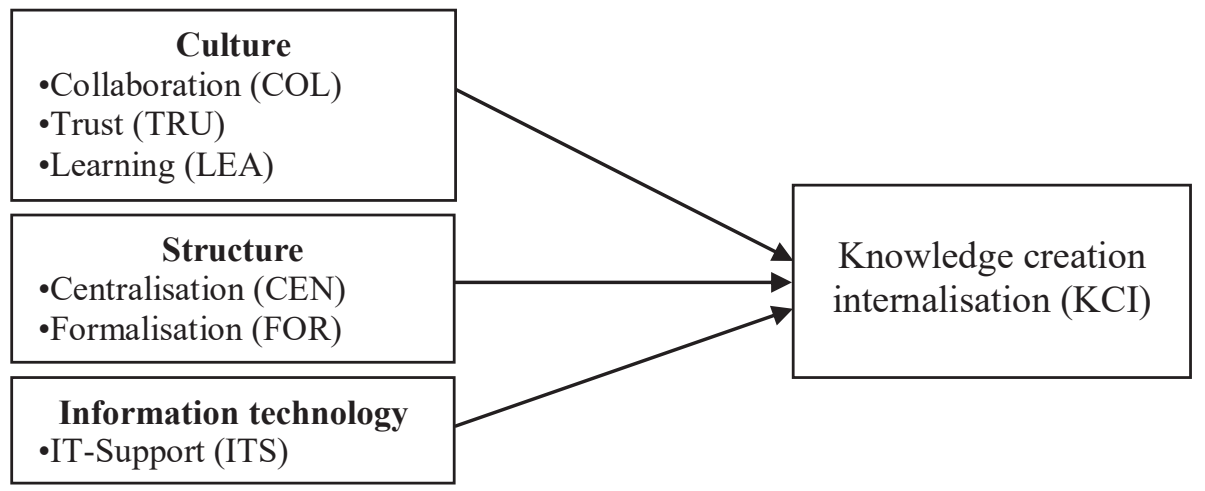

Figure 1. Conceptual framework.

The variables used in the framework are explained below:

Knowledge management enablers

Knowledge management enablers (or influencing factors) are organisational mechanism for fostering knowledge consistently (Ichijo, Krogh \& Nonaka, 1998), those are also the necessary building blocks in the improvement of the effectiveness of activities for knowledge management (Ichijo et al. 1998; Stonehouse \& Pemberton, 1999).

\section{Culture}

Choi (2002) stated that culture is a basic building block of knowledge management. The organisation culture can be defined as both the set of values, philosophy and mission of the organisation, as well as the unspoken set of values that guide the employee's actions and perceptions in the organisation (McDermott \& O’Dell, 2001).

\section{Collaboration}

Collaboration is defined as the degree to which people in a group actively support and help each other in their work (Gupta \& Govindarajan, 2000). Collaborative interactions such as open discussion, social interaction, and joint activity can help to create organisational knowledge (Hedlund, 1994).

\section{Trust}

Trust can be defined as maintaining reciprocal faith in each other in terms of intention and behaviors (Hurley \& Hult, 1998). Trust can facilitate open, substantive, and persuasive information exchange (Iansiti, 1993; Hansen, Nohria \& Tierney, 1999). 
Learning

Learning is explained as the acquisition of new knowledge by people who are able and willing to apply that knowledge to make decisions or influence others (Krogh, 1998). For the organisations to be successful in knowledge creation, traditional training and development activities may no longer suffice; they need to nurture an environment with continuous and persisting learning (Lubit, 2001; Eppler \& Sukowski, 2000).

\section{Centralisation}

Centralisation refers to the locus of decision authority and control within an organisational entity (Lee \& Choi, 2003). The concentration of decision-making authority inevitably reduces creative solutions while the dispersion of power facilitates spontaneity, experimentation, and the freedom of expression, which are the lifeblood of knowledge creation (Graham \& Pizzo, 1996).

\section{Formalisation}

Formalisation refers to the degree to which decisions and working relationships are managed by formal rules, procedures, and standard policies (Chase, 1998; Hopper, 1990; Zucker, Darby, Brewer \& Peng, 1996). Knowledge creation requires flexibility rather than work rules (Bennett \& Gabriel, 1999).

\section{IT Support}

Information Technology facilitates quick search, access of information, cooperation and communication between organisational members (Yeh, Lai \& Ho 2006). Information technology can provide an edge in harvesting knowledge (Bhatt, 2000).

\section{Knowledge Creation Internalisation}

This internalisation requires, firstly, the updating of the concepts or methods explicit and, secondly, the inclusion of such explicit knowledge into tacit (Nonaka \& Konno, 1998) uses some tools such as metaphor.

\section{METHODOLOGY}

To examine knowledge management enablers for knowledge creation internalization in the Nepalese hospitality industry, the study used the descriptive research design based on the survey. The descriptive research design is applied to develop an understanding of the research issue. The study has used primary data collected from executives, managers, department heads, sales officers, marketing officers, finance officers, guest relation officers, public relation officers and human resource managers in the hospitality industry. In the process of gathering information, a set of structured questionnaire was used as the main instrument. The primary data were collected by 'delivery and collection' methods. 
The target population is the employees of the hospitality industry working at top, middle and operation levels. The representative samples were selected to gather information about the hospitality industry's knowledge management for creativity and performance. Twostage sampling was adopted to determine and select the samples. Samples were drawn from the hospitality industry namely a) hotels, and b) travel/trekking agencies. In the study, two stages of the sampling method were applied. In the first stage, the large pool of 522 numbers of hotels, 444 numbers of travel agencies and 1244 numbers of trekking agencies within Kathmandu Valley as mentioned in the Statistical Year Book of Nepal (CBS, 2013) were the population for this study. Based on the sample frame and method adopted, a total of 38 hotels and 59 travel and trekking agencies were selected as samples for this study. In the second stage, the pool of 4033 employees from the selected sample hotels, travel agencies and trekking agencies was defined as the population. The sample adequacy for the present study was tested as suggested by Cochran (1999).

A total of 458 responses was collected from 97 firms. Due to incomplete data, 76 responses were eliminated. Consequently, 382 responses from 97 firms were taken for further analysis. The total response rate was 83 percent. Self-administered questionnaires were used to collect the perceptive opinions from the respondents.

Questionnaire items developed included a list of 52 items to measure the different constructs in the study: collaboration, trust, learning, centralisation, formalisation, information technology and knowledge creation internalisation. The development of the items was done by re-evaluating intensively the literature review related to the concepts and constructs stated in the integrative view. This empirical research aims to test whether the dimensions proposed in the above-mentioned integrative view support a significant distinction between different kinds of knowledge management enablers.

To validate the proposed research model, this study conducted a pre-test. The pre-test was conducted in November 2014. For the pre-test survey, this study developed a questionnaire and collected data from 36 potential respondents of the selected samples: both hotels (20) and travel/trekking agencies of 16 respondents. Based on the findings of the pretest survey, the research questionnaire was modified to improve the reliability and validity of the study. After the pre-test, the questionnaire was finalised and the main study was conducted. The questionnaires were administered in December 2014 and it took five months to complete the survey.

The study used regression analysis to test the interrelationship of knowledge management enablers (independent variables) similarly their impact on knowledge creation internalization (dependent variables). The application of regression analysis to the present study is desirable as it significantly helps researchers evaluate the causal effect of one variable on other variables. 


\section{Regression Equation Model between KCI and KMEs}

Regression equation between the knowledge creation internalisation and knowledge management enablers as follows:

$$
K C I=\alpha+\beta_{1} C O L+\beta_{2} T R U+\beta_{3} L E A+\beta_{4} C E N+\beta_{5} F O R+\beta_{6} I T S+E
$$

Where,

$\mathrm{KCI}=$ knowledge creation internalisation

$\alpha=$ constant number

$\beta_{1}=$ change in knowledge creation internalisation associated with a unit change in collaboration

$\beta_{2}=$ change in knowledge creation internalisation associated with a unit change in trust

$\beta_{3}=$ change in knowledge creation internalisation associated with a unit change in learning

$\beta_{4}=$ change in knowledge creation internalisation associated with a unit change in centralisation

$\beta_{5}=$ change in knowledge creation internalisation associated with a unit change in formalisation

$\beta_{6}=$ change in knowledge creation internalisation associated with a unit change in information technology

$\mathrm{COL}=$ collaboration

TRU $=$ trust

LEA $=$ learning

$\mathrm{CEN}=$ centralisation

$\mathrm{FOR}=$ formalisation

ITS = information technology

$\mathrm{E} \quad=$ prediction error (residual)

\section{Hypotheses}

The study hypotheses were largely derived from theoretical statements made in the literature on knowledge management. In the first hypothesis, the study analyzed the collaboration dimension of knowledge management enabler. In the second and third hypotheses, the study analyzed the trust and learning dimension. In the fourth, fifth and sixth hypotheses, the study analyzed the centralisation, formalisation and information technology support dimension. 


\section{Hypothesis 1: Collaboration}

The study proposes to analyse the collaboration for knowledge creation internalisation. The following hypotheses have been formulated:

The null hypothesis, $H_{0}$ : Collaboration does not affect knowledge creation internalisation.

The alternative hypothesis, $H_{1}$ : Collaboration affects knowledge creation internalization positively.

The acceptance of the alternative hypothesis associated with hypothesis 1 implies that collaboration will have a positive effect on the knowledge creation internalization and it points to the effective role of collaboration on knowledge creation internalisation. On the other hand, if the tests reject the alternative hypotheses and it may suggest that the collaboration is not helpful for knowledge creation internalisation.

Hypothesis 2: Trust

After determination of the collaboration for knowledge creation internalisation, the study proposes to evaluate the trust dimension of knowledge creation internalisation. To test the trust for knowledge creation internalisation, the testable hypotheses have been formulated:

The null hypothesis, $H_{0}$ : Trust does not affect knowledge creation internalisation. The alternative hypothesis, $\mathrm{H}_{2}$ : Trust affects knowledge creation internalization positively.

The acceptance of the alternative hypothesis associated with hypothesis 2 implies that trust will have a positive effect on the knowledge creation internalisation and it points to the effective role of trust on knowledge creation internalisation. On the other hand, if the tests reject the alternative hypotheses, it will suggest that trust does not play an important role in knowledge creation internalisation.

\section{Hypothesis 3: Learning}

After determination of the trust for knowledge creation internalisation, the study proposes to evaluate the learning for knowledge creation internalisation. To test the learning for knowledge creation internalisation, the testable hypotheses have been formulated:

The null hypothesis, $H_{0}$ : Learning does not affect knowledge creation internalisation. The alternative hypothesis, $H_{3}$ : Learning affects knowledge creation internalisation positively. 
The acceptance of alternative hypothesis associated with hypothesis 3 implies that learning will have a positive effect on knowledge creation internalisation and it points to the effective role of learning on knowledge creation internalisation. On the other hand, if the tests reject the alternative hypotheses, it may suggest that learning does not play an important role in knowledge creation internalisation.

\section{Hypothesis 4: Centralisation}

After determination of the learning for knowledge creation internalisation, the study proposes to evaluate the centralisation for knowledge creation internalisation. To test the centralisation for knowledge creation internalisation, the testable hypotheses have been formulated:

The null hypothesis, $H_{0}$ : Centralisation does not affect knowledge creation internalisation. The alternative hypothesis, $H_{4}$ : Centralisation affects knowledge creation internalisation negatively.

The acceptance of the alternative hypothesis associated with hypothesis 4 implies that centralisation will have a negative effect on the knowledge creation internalisation and it points to the negative effect of centralisation for knowledge creation internalisation. On the other hand, if the tests reject the alternative hypotheses and it may suggest that centralisation does not play an important role in knowledge creation internalisation.

\section{Hypothesis 5: Formalisation}

After determination of the centralisation for knowledge creation internalisation, the study proposes to evaluate the formalisation for knowledge creation internalisation. To test the formalisation for knowledge creationinternalisation, the testable hypotheses have been formulated:

The null hypothesis, $H_{0}$ : Formalisation does not affect knowledge creation internalisation. The alternative hypothesis, $H_{5}$ : Formalisation affects knowledge creation internalization negatively.

The acceptance of the alternative hypothesis associated with hypothesis 5 implies that formalisation will have a negative effect on the knowledge creation internalisation and it points to the negative effect of formalisation for knowledge creation internalisation. On the other hand, if the tests reject the alternative hypotheses and it may suggest that the formalisation does not play an important role in knowledge creation internalisation. 
Hypothesis 6: IT Support

After determination of the formalisation for knowledge creation internalisation, the study proposes to evaluate the IT support for knowledge creation internalisation. To test the IT support for knowledge creation internalisation, the testable hypotheses have been formulated:

The null hypothesis, $H_{0}$ : IT support does not affect knowledge creation internalisation.

The alternative hypothesis, $H_{6}$ : IT support affects knowledge creation internalisation positively.

The acceptance of the alternative hypothesis associated with hypothesis 6 implies that IT support will have a positive effect on the knowledge creation internalisation and it points to the effective role of IT support for knowledge creation internalisation. On the other hand, if the tests reject the alternative hypotheses and it may suggest that IT support does not play an important role in knowledge creation internalisation.

\section{RESULTS AND DISCUSSION}

Demographic data for the respondents of the main survey is presented in Table 1 and the estimated relationship between knowledge creation internalisation and fundamental variables in Table 1.

Table1 presents the demographic information of the respondents. Table 1 shows the gender of the majority of the respondents is male, comprising $63.6 \%$ however the remaining $36.4 \%$ are female. The highest percentage of the respondents belongs to the age between 20 35 followed by $24.1 \%$ for the age between $36-50$. Nearly half of the respondents $(46.9 \%)$ have a Bachelor's Degree. $28.5 \%$ of the respondents have a Master Degree and $24.1 \%$ of them have completed Higher Secondary Level, only $0.5 \%$ of the sampled managers have $\mathrm{Ph}$. D. Degree. The respondents who have work experience of $0-5$ years comprise $56.3 \%$ of the study sample; however, managers that have experience of 6-10 years comprise $13.6 \%$. Most of the managers (50.3\%) are married and $49.4 \%$ are single. Most of the respondents $(27 \%)$ work in the public relations department. Most of the respondents (47.9\%) are from the middle management level. 
Table 1

Demographic Data for the Respondents of the Main Survey

\begin{tabular}{|c|c|c|c|}
\hline Demographic variables & & Items & Percent $\%$ \\
\hline \multirow[t]{2}{*}{ Sex } & & Male & 63.6 \\
\hline & & Female & 36.4 \\
\hline \multirow[t]{5}{*}{ Manager's age } & $<20$ & & 4.5 \\
\hline & & $20-35$ & 66.2 \\
\hline & & $36-50$ & 24.1 \\
\hline & & $51-65$ & 4.7 \\
\hline & $>65$ & & 0.5 \\
\hline \multirow{4}{*}{$\begin{array}{l}\text { Manager's highest level of } \\
\text { education }\end{array}$} & & Higher secondary & 24.1 \\
\hline & & Bachelor's degree & 46.9 \\
\hline & & Master's degree & 28.5 \\
\hline & & Ph. D. & 0.5 \\
\hline \multirow[t]{5}{*}{ Manager's work experience } & $<5$ & & 56.3 \\
\hline & & $6-10$ & 13.6 \\
\hline & & $11-15$ & 12.0 \\
\hline & & $16-20$ & 7.4 \\
\hline & $>20$ & & 10.7 \\
\hline \multirow[t]{3}{*}{ Marital status } & & Married & 50.3 \\
\hline & & Single & 49.4 \\
\hline & & Others & 0.3 \\
\hline \multirow[t]{6}{*}{ Manager's current department } & & Human resources & 12.6 \\
\hline & & Finance/Accounting & 16.2 \\
\hline & & Sales & 24.8 \\
\hline & & IT & 5.0 \\
\hline & & Public relations & 27.0 \\
\hline & & Marketing & 14.4 \\
\hline \multirow[t]{3}{*}{ Manager's current position } & & Top management level & 11.3 \\
\hline & & $\begin{array}{l}\text { Middle management } \\
\text { level }\end{array}$ & 47.9 \\
\hline & & Operational level & 40.8 \\
\hline
\end{tabular}

Source: Questionnaire survey, 2015

In the context of collaboration, trust, learning, centralisation, formalisation and information technology variables are found to be essential for knowledge creation internalisation. Collaboration affects the knowledge creation internalisation in model $1(\beta=$ $0.415, \mathrm{p}>0.05$ ), which supports $\mathrm{H}_{1}$. It indicates that good coordination among different units and people in the organisation encourages learning through practice. The result is similar to Choi (2002), Lee and Choi (2000), and Migdadi (2005). But the study result is contradicted with Berraies et al. (2014) which found that collaboration is not related tointernalisation. The $\mathrm{R}^{2}(0.141)$ suggests that 14.10 percent of the variance of knowledge creation internalisation is explained by collaboration. Since F value is 62.284 , which is statistically significant at 5 percent level. It indicates that the model is statistically fit for further analysis. 
Table 2

Estimated Relationship between KCI and Fundamental Variables

\begin{tabular}{|c|c|c|c|c|c|c|c|c|c|c|}
\hline \multirow{2}{*}{$\begin{array}{c}\text { Mode } \\
I\end{array}$} & \multirow{2}{*}{$\begin{array}{c}\text { Intercep } \\
t\end{array}$} & \multicolumn{6}{|c|}{ Regression Coefficients of } & \multirow[t]{2}{*}{$R^{2}$} & \multirow{2}{*}{$\begin{array}{l}\text { Adj } \\
R^{2}\end{array}$} & \multirow[t]{2}{*}{$f$} \\
\hline & & $\mathrm{COL}$ & TRU & LEA & CEN & FOR & ITS & & & \\
\hline 1 & $\begin{array}{c}2.749 \\
(000)^{*}\end{array}$ & $\begin{array}{c}0.415 \\
(000)^{*}\end{array}$ & & & & & & 0.141 & 0.139 & $\begin{array}{l}62.284 \\
(000)^{*}\end{array}$ \\
\hline 2 & $\begin{array}{c}3.093 \\
(000)^{*}\end{array}$ & & $\begin{array}{l}0.352 \\
(000)^{*}\end{array}$ & & & & & 0.109 & 0.107 & $\begin{array}{l}46.462 \\
(000)^{*}\end{array}$ \\
\hline 3 & $\begin{array}{c}2.621 \\
(000)^{*}\end{array}$ & & & $\begin{array}{c}0.472 \\
(000)^{*}\end{array}$ & & & & 0.196 & 0.194 & $\begin{array}{l}92.926 \\
(000)^{*}\end{array}$ \\
\hline 4 & $\begin{array}{c}4.726 \\
(000)^{*}\end{array}$ & & & & $\begin{array}{c}0.047 \\
(0.215)\end{array}$ & & & 0.004 & 0.001 & $\begin{array}{c}1.541 \\
(0.215)\end{array}$ \\
\hline 5 & $\begin{array}{c}4.773 \\
(000)^{*}\end{array}$ & & & & & $\begin{array}{c}0.033 \\
(0.399)\end{array}$ & & 0.002 & -0.001 & $\begin{array}{c}0.713 \\
(0.399)\end{array}$ \\
\hline 6 & $\begin{array}{c}2.477 \\
(000)^{*}\end{array}$ & & & & & & $\begin{array}{c}0.493 \\
(000)^{*}\end{array}$ & 0.235 & 0.233 & $\begin{array}{c}116.549 \\
(000)^{*}\end{array}$ \\
\hline 7 & $\begin{array}{c}2.191 \\
(000)^{*}\end{array}$ & $\begin{array}{c}0.099 \\
(0.226)\end{array}$ & $\begin{array}{c}0.089 \\
(0.200)\end{array}$ & $\begin{array}{l}0.360 \\
(000)^{*}\end{array}$ & & & & 0.211 & 0.205 & $\begin{array}{l}33.745 \\
(000)^{*}\end{array}$ \\
\hline 8 & $\begin{array}{c}4.723 \\
(000)^{*}\end{array}$ & & & & $\begin{array}{c}0.046 \\
(0.364)\end{array}$ & $\begin{array}{c}0.002 \\
(0.966)\end{array}$ & & 0.004 & -0.001 & $\begin{array}{c}0.769 \\
(0.464)\end{array}$ \\
\hline 9 & $\begin{array}{c}1.598 \\
(000)^{*}\end{array}$ & $\begin{array}{c}-0.024 \\
(0.768)\end{array}$ & $\begin{array}{c}0.076 \\
(0.251)\end{array}$ & $\begin{array}{c}0.276 \\
(000)^{*}\end{array}$ & $\begin{array}{l}-0.026 \\
(0.552)\end{array}$ & $\begin{array}{c}0.015 \\
(0.740)\end{array}$ & $\begin{array}{c}0.355 \\
(000)^{*}\end{array}$ & 0.298 & 0.287 & $\begin{array}{l}26.539 \\
(000)^{*}\end{array}$ \\
\hline
\end{tabular}

Note. (1) Figures in parentheses are p-values. (2) The asterisk signs (*) and (**) denote that the results are significant at 1 percent and 5 percent level respectively.

Source: Questionnaire survey, 2015

In model 2, trust is a positive significant predictor of the knowledge creation internalisation $(\beta=0.352, p>0.05)$, which supports $\mathrm{H}_{2}$. It indicates that the mutual faith actualizes concepts about strategy, tactics and innovation. The result is similar to Choi (2002), Lee and Choi (2000), and Migdadi (2005). But the study result is contradicted with Berraies et al. (2014) which found that trust is not related tointernalisation. The $\mathrm{R}^{2}(0.109)$ suggests that 10.90 percent of the variance of knowledge creation internalisation is explained by the trust. Since in model F value is 46.462 , which is statistically significant at 5 percent level. It indicates that the model is statistically fit for further analysis.

From Table 2, it is clear that learning is a positive significant predictor of the knowledge creation internalisation $(\beta=0.472, \mathrm{p}<0.05)$ in model 3 , which supports $\mathrm{H}_{3}$. It indicates that the learning programme promotes the absorption of new knowledge. So the Nepalese hospitality industry must give more precedence to develop training, seminars and 
community gathering programmes for creativity. Similarly, the result is consistent with the studies of Choi (2002), Lee and Choi (2000), Berraies et al. (2014) and Migdadi (2005) from a learning viewpoint. The $\mathrm{R}^{2}(0.196)$ suggests that 19.60 percent of the variance of knowledge creation internalisation is explained by learning. Also from the table, it is clear that the $\mathrm{F}$ value is 92.926 , which is statistically significant at 5 percent level. It indicates that the model is statistically fit for further analysis.

In table centralisation is not a significant predictor of the knowledge creation internalisation in model $4(\beta=0.047, p>0.05)$ which is contrary to the study expectation, centralisation has no effect on the knowledge creation internalisation, indicating that it does not support $\mathrm{H}_{4}$. It indicates that the centralisation does not affect on absorption of knowledge. This result is similar to Migdadi (2005). But the study result contradicts with Choi (2002), Berraies et al. (2014), and Lee and Choi (2000) which found that centralisation is a significant negative predictor of internalisation. The $\mathrm{R}^{2}(0.004)$ suggests that 0.40 percent of the variance of knowledge creation internalisation is explained by centralisation. Since in model $F$ value is 1.541 , which is statistically insignificant at 5 percent level. It indicates that the model is not statistically fit for further analysis.

From Table 2, it is clear that formalisation does not affect the knowledge creation internalisation in model $5(\beta=0.033, \mathrm{p}>0.05)$, which is contrary of the study expectation, formalisation has no effect on the knowledge creation internalizaton, indicating that it does not support $\mathrm{H}_{5}$. It indicates that the standard policies do not impact on the knowledge creation internalisation. So it means no need to change formal rules to promote learning through practice. Similarly, the result is consistent with Choi (2002), Lee and Choi (2000), Berraies et al. (2014) and Migdadi (2005) from the formalisation viewpoint. The $\mathrm{R}^{2}(0.713)$ suggests that 71.30 percent of the variance of knowledge creation internalisation is explained by formalisation. Since F value is 0.713 which is statistically insignificant at 5 percent level. It indicates that the model is not statistically fit for further analysis.

In model 6, information technology is a positive significant predictor of the knowledge creation internalisation $(\beta=0.493$, $\mathrm{p}<0.05)$, which supports $\mathrm{H}_{6}$. It indicates that information technology encourages to absorption of explicit knowledge into tacit. The result is similar to Berraies et al. (2014), but the study result contradicts with Choi (2002), Lee and Choi (2000), and Migdadi (2005), which found that information technology is not a good predictor of internalisation. In the model, the $\mathrm{R}^{2}(0.235)$ suggests that 23.50 percent of the variance of knowledge creation internalisation is explained by information technology. As $\mathrm{F}$ value is 116.549 , which is statistically significant at 5 percent level. It indicates that the model is statistically fit for further analysis.

In model 7, when all the fundamental cultural variables are simultaneously included, the $p$-statistics of learning $(\beta=0.360, p<0.5)$ is significant. The result suggests that learning is more important in predicting knowledge creation internalisation than collaboration and 
trust. The $\mathrm{R}^{2}(0.211)$ suggests that 21.10 percent of the knowledge creation internalisation variance is explained by three variables such as collaboration, trust and learning. As $F$ value is 33.745 , which is statistically significant at 5 percent level. It indicates that the model is statistically fit for further analysis.

When all the fundamental structural variables are simultaneously included, centralisation and formalisation in model 8 , do not significantly affect the knowledge creation internalisation. In the model, the $\mathrm{R}^{2}(0.004)$ suggests that 0.40 percent of the knowledge creation internalisation variance is explained by two variables such as centralisation and formalisation. Also from the table, it is clear that $\mathrm{F}$ value is 0.769 , which is statistically insignificant at 5 percent level. It indicates that the model is not statistically fit for further analysis.

In model 9, when all the fundamental variables are simultaneously included, the $\mathrm{p}$ statistics of learning $(\beta=0.276, p<0.05)$ and information technology $(\beta=0.355, p<0.05)$ have been found to be significant. The result suggests that learning and information technology are more important in predicting knowledge creation internalisation than other variables. Model 9 suggests that learning and information technology are more informative than collaboration, trust, centralisation and formalisation. The $\mathrm{R}^{2}(0.298)$ suggests that 29.80 percent of the knowledge creation internalisation variance is explained by six variables such as collaboration, trust, learning, centralisation, formalisation and information technology. Since $\mathrm{F}$ value is 26.539 , which is statistically significant at 5 percent level. It indicates that the model is statistically fit for further analysis.

The regression results of knowledge creation internalisation on collaboration, trust, learning, centralisation, formalisation, and information technology. The alternative specifications of the models reveal the positive relationship of knowledge creation internalisation with collaboration, trust, learning and information technology, whereas, an insignificant relationship of the knowledge creation internalisation with centralisation and formalisation. Models 1 to 3 and 6 show that there is a significant relationship between the knowledge creation internalisation on collaboration, trust, learning and information technology.

The knowledge creation internalisation is positively influenced by collaboration, trust, learning, and information technology, and not significantly influenced by centralization and formalisation. The overall results show the positive relationship of knowledge creation internalisation with collaboration, trust, learning, and information technology, and not with centralisation and formalisation. 


\section{CONCLUSION}

The study results have revealed the culture as the most vital enabler of knowledge creation-internalisation. Thus, building and supporting a culture that rewards and encourages employees for seeking, sharing, formalising and creating knowledge attributes will most probably lead to the successful capture, absorption, creation and implementation of knowledge management. Good information technology support is also an important enabler of knowledge creation internalization. Enabler such as structure is not significantly related to the knowledge creation internalisaiton.

The purpose of the study was firstly to gain a better understanding of which enablers are critical for the successful implementation of knowledge management and secondly to test the strong positive impact of knowledge management enablers on knowledge creation processes proposed by many KM theory developers covered in the literature review section. It was an empirical study which contributed to the validation of some of the assumptions made regarding enabler factors and their impact on knowledge creation internalisation of the hospitality industry in Nepal.

\section{REFERENCES}

Alavi, M., \& Leidner, D. E. (2001). Knowledge management and knowledge management systems: Conceptual foundations and research issues. MIS Quarterly, 25(1), 107-136.

Bennett, R., \& Gabriel, H. (1999). Organizational factors and knowledge management within large marketing departments: An empirical study. Journal of Knowledge Management, 3(3), 212-225.

Berraies, S., Chaher, M., \& Yahia, K. B. (2014). Knowledge management enablers, knowledge creation process and innovation performance: An empirical study in Tunisian information and communication technologies sector. Business Management and Strategy, 5(1), 1-26.

Bhatt, G. (2000). Organizing knowledge in the knowledge development cycle. Journal of Knowledge Management, 4(1), 15-26.

Bloor, G., \& Dawson, P. (1994). Understanding professional culture in organizational context. Organization Studies, 15(2), 275-295.

Bolloju, N., Khalifa, M., \& Turban, E. (2002). Integrating knowledge management into enterprise environments for the next generation decision support. Decision Support Systems, 33(2), 163-176.

Caruana, A., Morris, M. H., \& Vella, A. J. (1998). The effect of centralization and formalization on entrepreneurship in export firms. Journal of Small Business Management, 36(1), 16-29.

Chalise, M. (2006). Knowledge management: An evidence from the Nepalese banking industry (Unpublished M. Phil. dissertation). Office of the Dean, Faculty of Management, Tribhuvan University, Nepal. 
Chalise, M. (2011). Knowledge management: A comparative study of public and private commercial banking sector undertakings in Nepal (Unpublished doctoral dissertation). Office of the Dean, Faculty of Management, Tribhuvan University, Nepal.

Chase, R. L. (1998). The people factor. People Management, 22, 38.

Chaudhary, M. K. (2016). Strategic alignment of knowledge management for organizational performance in Nepal (Unpublished doctoral dissertation). Office of the Dean, Faculty of Management, Tribhuvan University, Nepal.

Choi, B. (2002). Knowledge management enablers, processes, and organization performance: An integration and empirical examination (Unpublished doctoral dissertation). Division of Management Engineering, Korea Advanced Institute of Science of Technology, Korea.

Cochran, W. G. (1999). Sampling Techniques ( $3^{\text {rd }}$ ed.). Singapore: John Wiley \& Sons.

Coleman, D. (1999). Groupware: Collaboration and knowledge sharing. In J. Liebowitz (Eds.), Boca Raton: CRC Press, Knowledge Management Handbook, 11(1), 11-23.

De Long, D. W., \& Fahey, L. (2000). Diagnosing cultural barriers to knowledge management. The Academy of Management Executive, 14(4), 113.

Eppler, M. J., \&Sukowski, O. (2000). Managing team knowledge: Core processes, tools and enabling factors. European Management Journal, 18(3), 334-341.

Graham, A. B., \& Pizzo, V. G. (1996). A question of balance: Case studies in strategic knowledge management. European Management Journal, 14(4), 338-346.

Gupta, A. K., \& Govindarajan, V. (2000). Knowledge management's social dimension: Lessons from nucor steel. MIT Sloan Management Review, 42(1), 71.

Hansen, M. T., Nohria, N., \& Tierney, T. (1999). What's your strategy for managing knowledge? Harvard Business Review, 77(2), 106-115.

Hedlund, G. (1994). A model of knowledge management and the $\mathrm{N}$-form corporation. Strategic Management Journal,15, 73-90.

Hopper, M. D. (1990). Rattling SABRE-new ways to compete on information. Harvard Business Review, 68(3), 118-125.

Hurley, R., \& Hult, T. (1998). Innovation, market orientation, and organizational learning: An integration and empirical examination. Journal of Marketing, 62(3), 42-54.

Iansiti, M. (1993). Real-world R\&D: Jumping the product generation gap. Harvard Business Review, 71(3), 138-147.

Ichijo, K., Krogh, G., \& Nonaka, I. (1998). Knowledge enablers. In G. Krogh, J. Roos, \& D. Kleine (Eds.), Knowing in companies (173-203). Thousand Oaks, CA: Sage. 
Jarvenpaa, S. L., \& Staples, D. S. (2000). The use of collaborative electronic media for information sharing: An exploratory study of determinants. Strategic Information Systems, 9, 129-154.

Jeng, D. J. F., \& Dunk, N. (2013). Knowledge management enablers and knowledge creation in ERP system success. International Journal of Electronic Business Management, 11(1), 49-59.

Johnson, G. (1992). Managing strategic change-strategy, culture and action. Long Range Planning, 25(1), 28-36.

Kandel, L. R. (2015). Knowledge management in Nepalese Telecom Industry (Unpublished M. Phil. dissertation). Office of the Dean, Faculty of Management, Tribhuvan University, Nepal.

Kreitner, R., \& Kinicki, A. (1992). Organizational behaviour. Homewood: Richard D. Irwin.

Krogh, G. V. (1998). Care in the knowledge creation. California Management Review, 40(3), 133-153.

Kuhlen, R. (2003). Change of paradigm in KM - Framework for the collaborative production and exchange of knowledge, IFLA publications, 1-19.

Lee, H., \& Choi, B. (2000). Knowledge management enablers, processes and organizational performance: An integration and empirical examination. Retrieved from http://cis.kaist.ac.kr/Research/file/128.pdf

Lee, H., \& Choi, B. (2003). Knowledge management enablers, processes and organizational performance: An integrative view and empirical examination. Journal of Management Information System, 20, 179-228.

Li, C. Y., \& Hsieh, C. T. (2009). The impact of knowledge stickiness on knowledge transfer implementation, internalization, and satisfaction for multinational corporations. International Journal of Information Management, 29(6), 425-435.

Long, D. D. (1997). Building the knowledge-based organizations: How culture drives knowledge behaviors. Working paper of the Center for Business Innovation, Ernst \& Young LLP, Cambridge, MA.

Luan, J., \& Serban, A. M. (2002). Technologies, products, and models supporting knowledge management. New Directions for Institutional Research, 13(113), 85-104.

Lubit, R. (2001). Tacit knowledge and knowledge management: The keys to sustainable competitive advantage. Organizational Dynamics, 29(4), 164-178.

McDermott, R., \& O'Dell, C. (2001). Overcoming cultural barriers to sharing knowledge. Journal of Knowledge Management, 5(1), 76-85.

Migdadi, M. M. (2005). An integrative view and empirical examination of the relationships among knowledge management enablers, processes and organizational performance in Australian Enterprises (Unpublished doctoral dissertation). School of Economics and Information Systems, University of Wollongong, Australia. 
Nelson, K. M., \& Cooprider, J. G. (1996). The contribution of shared knowledge to IS group performance. MIS Quarterly, 20(4), 409-429.

Ng, P. K., Goh, G. G. G., \& Eze, U. C. (2011). The role of knowledge management in product development performance: A review. Journal of Knowledge Management Practice, 12(1), 1-15.

Nonaka, I. (1991). The knowledge-creating company. Harvard Business Review, 96-104.

Nonaka, I. (1994). A dynamic theory of organizational knowledge creation. Organization Science, 5(1), 14-37.

Nonaka, I., \& Konno, N. (1998). The concept of Ba: Building a foundation for knowledge creation. California Management Review, 40(3), 40-54.

Nonaka, I., \& Takeuchi, H. (1995). The knowledge-creating company: How Japanese companies create the dynamics of innovation. Oxford: Oxford University Press.

Nonaka, I., \& Toyama, R. (2003). The knowledge-creating theory revisited: Knowledge creation as a synthesizing process. Knowledge Management Research \& Practice, l(1), 2-10.

Nonaka, I., Toyama, R., \& Nagata, A. (2000). A firm as a knowledge-creating entity: A new perspective on the theory of the firm. Industrial and Corporate Change, 9(1), 1-20.

Robinson, H., Carrillo, P., Anumba, C., \& Al-Ghassani, A. (2005). Knowledge management practices in large construction organizations. Engineering, Construction and Architectural Management, 12(5), 431-445.

Scarbrough, H., Swan, J., \& Preston, J. (1999). Issues in People Management: Knowledge Management: A Literature Review, Institute of Personnel and Development. Trowbridge: The Cromwell Press.

Schein, E. H. (1985). Organizational culture and leadership. San Francisco, CA: JosseyBass.

Scott, J. E. (2000). Facilitating interorganizational learning with information technology. Journal of Management Information Systems, 17(2), 81-113.

Stonehouse, G. H., \& Pemberton, J. D. (1999). Learning and knowledge management in the intelligent organization. Participation \& Empowerment: An International Journal, 7(5), 131-144.

Swap, W., Leonard, D., Shields, M., \& Abrams, L. (2001). Using mentoring and storytelling to transfer knowledge in the workplace. Journal of Management Information Systems, 18(1), 95-114.

Teece, D. J. (2000). Strategies for managing knowledge assets: The role of firm structure and industrial context. Long Range Planning, 33(1), 35-54.

Vaccaro, A., Veloso, F., \& Brusoni, S. (2009). The impact of virtual technologies on knowledge-based processes: An empirical study. Research Policy, 38(8), 1278-1287. 
Yeh, Y., Lai, S., \& Ho, C. (2006). Knowledge management enablers: A case study. Industrial Management and Data Systems, 106(6), 793-810.

Zucker, L. G., Darby, M. R., Brewer, M. B., \& Peng, Y. (1996). Collaboration structures and information dilemmas in biotechnology: Organization boundaries as trust production. In R. M. Kramer, \& T. R. Tyler (Eds.), Trust in Organizations: Frontiers of Theory and Research (90-113). Thousand Oaks, CA: Sage. 